Research Article

\title{
Enhancing design method training with insights from educational research-improving and evaluating a training course for a qualitative modelling method
}

\author{
Patric Grauberger $^{1}$ D $\cdot$ Matthias Eisenmann ${ }^{1}$ (D) Julian Stoitzner ${ }^{1} \cdot$ Sven Matthiesen $^{1}$ (D)
}

Received: 22 April 2021 / Accepted: 21 September 2021

Published online: 02 October 2021

(c) The Author(s) $2021 \quad$ OPEN

\begin{abstract}
This study presents an approach for identification and elimination of challenges in modelling in embodiment design. These challenges can be caused either by the modelling method or the corresponding training course. To investigate the efficacy of a modelling method, first challenges of the corresponding training course need to be addressed. The study is conducted at a training course of the modelling method of the Contact and Channel Approach. A situation analysis of the training course is conducted in three application with 45 participants. Based on the findings, the training course is improved through application of insights from educational research that correspond to the identified challenges. A concluding evaluation takes place with 20 participants. The improvement of the training course takes place based on identification of challenges in the four areas of didactic elements, content structure, visualization and practical modelling in evaluations. Modularization is needed for purposeful training of different target groups. An issue regarding the practical modelling indicates a clearer view on the efficacy of the modelling method.
\end{abstract}

\section{Article highlights}

- Identification of challenges in a training course for qualitative modelling in embodiment design through free text evaluation in three applications.
- Clustering of the evaluation results enabled identification of suitable findings from educational research to eliminate challenges in the training course.

- Conflicts of objectives regarding content and time can be addressed by modularization, however, this increases the effort needed for investigations.

Keywords Embodiment design $\cdot$ Modelling $\cdot$ Engineering training $\cdot$ Educational research $\cdot$ Contact and Channel Approach

\section{Introduction}

Many situations in embodiment design require quick decisions based on few available resources. Here, qualitative modelling plays an important role through support of thinking processes in ideation and technical analyses. Reasons for their application can be missing information in early stages of embodiment design or shortage of resources necessary for quantitative models like models based on the finite element method (FEM) or multibody

Patric Grauberger, Patric.grauberger@kit.edu | 'IPEK - Institute of Product Engineering, Karlsruhe Institute of Technology (KIT), Kaiserstr. 10, 76131 Karlsruhe, Germany. 
simulations. This becomes especially important in agile approaches, where many decisions have to be made based on scarce resources [1].

In embodiment design, most of the qualitative models are used early in conceptualization and ideation. Here, quick visualization of ideas without interference with the designer's creativity is important. Modelling methods here support mostly in how to draw quick and precise sketches. Examples are the free sketch [2] or Organ Domain models [3]. Training courses for these modelling methods are partially investigated e.g. in perspective sketching, where the training shows benefits of this method compared to a traditional sketching course [4].

In later phases of embodiment design, qualitative models are used to support product structuring or quantitative gain of insights through multibody simulation models or models based on finite element methods. Examples here are the design structure matrix (DSM) [5], bond graphs [6], Characteristics Properties modelling (CPM) [7] and many more (see also Matthiesen et al. [8]). For models like DSM and bond graphs, which are developed in large international communities, text books with explicit model building methods exist as well as lectures and training courses. For most of the more specific qualitative models like CPM, model building support is scarce. Here, often not even a model building method exists. However, for all of these models, no insights about efficacy or challenges from training courses has been identified.

For the transition from early conceptualization to quantitative modelling, models exist that are used to gain insights into relations of embodiment and system behavior. An example here is the Contact and Channel Approach (C\&C$C^{2}$-Approach) $[9,10]$, which has been developed to support design engineers in their thinking processes during embodiment design. For this approach, a modelling method has been derived as well as a training course. As for most of the other qualitative models for embodiment design, no insights into the efficacy and influence of the training course on the modelling are present.

An investigation regarding the $C \& C^{2}$-Approach shows that even experts in modelling with this approach sometimes have difficulties in using it in a purposeful way [11]. These experts have learned about the $C \& C^{2}$-Approach in their education and have access to literature describing its theory as well as application examples and the training course. Investigations regarding model usage also show, that this approach is seldom used in modelling practice [12]. These findings are similar to findings about the CPM [13] and indicate that difficulties in learning an approach can hinder its prevalence in design research and practice.

The present learning possibilities seem not to be sufficient to enable researchers and design engineers to use the $C \& C^{2}$-Approach according to its purpose. This is a critical point in the research around the $C \& C^{2}$-Approach. Studies showing the support of the built up models in engineering design tasks are already present as illustrative case studies (e.g. $[14,15])$. An experimental investigation shows the benefit of working with $C \& C^{2}$-Models that were built up by modelling experts [16]. However, it is very difficult to become a modelling expert with the given support. It also remains unclear, where difficulties in learning the $C \& C^{2}$-Approach emerge.

The problem derived from these investigations is a lack of knowledge about the influence of challenges emerging from the training course. The research question derived from this problem is as follows:

How can challenges emerging from a training course for a modelling method be identified and eliminated in embodiment design?

In this contribution, the research question will be answered at the example of the $C \& C^{2}$-Approach, as this modelling approach meets the prerequisites of an existing training course and missing insights about emerging challenges.

Aim of this contribution is therefore the investigation of challenges in the existing training course for the $C \& C^{2}$-Approach and its corresponding improvement. This training course is the basis for further research into modelling with the $C \& C^{2}$-Approach as well as comprehensive training for engineers in industry. For this, it is planned to adapt insights from educational research into the training course.

The following passages of section 1 give an overview of modelling with the $C \& C^{2}$-Approach (Section 1.1), the existing training course concept (Section 1.2) and insights from educational research (Section 1.3). Section 2 describes the research methodology for this investigation, where a situation analysis of the training course concept lays the basis for a subsequent improvement. A concluding evaluation investigates the effect of the taken measures regarding the efficacy of the training course. Section3 shows the results of situation analysis, improvement and evaluation. They are discussed in section 4 and an outlook is given in section 5 .

\subsection{The C\&C$C^{2}$-Approach}

For easier understanding of this contribution, this section gives a short summary of the $C \& C^{2}$-Approach.

This section is based on [15]. Parts of the following text are taken from that paper without changes.

The $C \& C^{2}$-Approach is a thinking tool for embodiment design. Its aim is to support design engineers in recognizing function-related parameters of the embodiment. As a meta-model it contains elements and rules to build up explicit $C \& C^{2}$-Models. It consists of three key elements 
and three basic hypotheses that define the usage of its key elements. An overview of the three key elements Working Surface Pair (WSP), Channel and Support Structure (CSS) and Connector (C) is depicted in Fig. 1. A WSP describes the interface where parts of the system connect while it fulfils its function. The CSS goes through system parts and connects the WSP. A CSS can include parts of components or whole subsystems depending to the modelling purpose. The Cs represent a model of the surrounding systems and transmit influences from outside the system boundaries into the system [16]. The basic hypotheses describe possibilities and boundaries of the modelling with the $C \& C^{2}$ Approach. They are depicted in Fig. 1 (right side). [15]

A C\&C ${ }^{2}$-Model (Fig. 1, center) is derived by using the key elements and basic hypotheses. For modelling statedependent embodiment function relations, the $C \& C^{2}$ Sequence model is used, where the created $C \& C^{2}$-Models are structured according to their temporal sequence and also different levels of detail can be considered. [15]

\subsection{Concept of the training course for the $\mathbf{C} \& \mathrm{C}^{2}$-Approach}

Basis for this research is the course concept, which was developed in 2017 based on the C\&C $C^{2}$-Approach through reworked definitions, lectures and discussions during the writing of the chapter on embodiment design in the $9^{\text {th }}$ edition of the Pahl/Beitz [9]. Expert knowledge was also included through publication analysis and workshops with the originators. Finally, example systems present at the
IPEK-Institute of Product Engineering were worked up for the course concept. The constructive alignment is used to harmonize learning objectives and content and to ensure adequate teaching and also learning control.

The course concept is structured like a classic training with theoretical input on the method and two application examples. It consists of an introduction, a theoretical part and three practical parts, from which one is designed as a common modelling task with the trainer. The purpose of the first practical part is to let the participants experience difficulties in building up an understanding of the system themselves using the example of a snap fit connection. Here the participants proceed intuitively, no methodical support is given.

In the practical parts, 2 computers with computer-aided design (CAD) software and each a CAD-expert for modelling the ideas of the participants are present. The modelled ideas of the snap fit connections are then exported from CAD as pdf drawings, which are transferred to two laser cutters and manufactured using highly dense fibre (HDF) plates. The manufacturing needs about $17 \mathrm{~s}$ per snap fit connection and from one plate, about 1000 snap fit connections can be manufactured. This eliminates the bottleneck created by other manufacturing technologies (milling, turning or even 3D printing need significantly more time) and enables the manufacturing of many iterations in one training course. After manufacturing, a validation environment is used to test the manufactured parts. A mounting device supports assembly of the parts. An electronic suitcase scale is used to test the maximal force of the

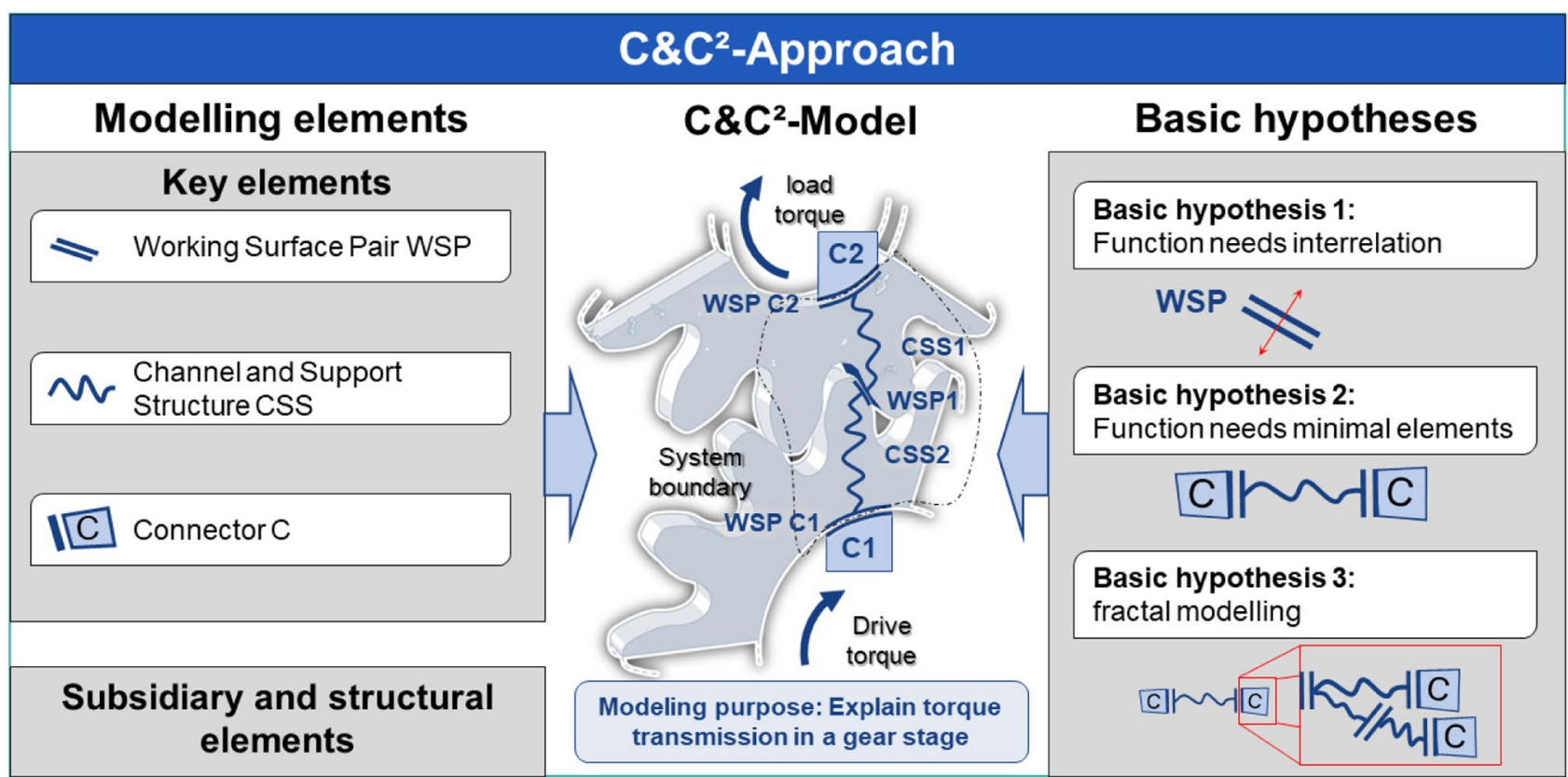

Fig. 1 The $C \& C^{2}$-Approach according to [17] 
snap fit connection. Objectives are that a certain force has to be reached five times. Therefore influences on the maximal force have to be considered as well as limited wear.

In the subsequent theoretical part, the $C \& C^{2}$-Approach is taught using an example from corporate practice and current modelling examples. Subsequently, a common model building is carried out using the example of a wedge lock washer.

Then, a second practical part with identical tasks to the first practical part and methodological support is carried out. At the end of the course, a summary is given and the evaluation takes place. An overview of the training course is shown in Fig. 2.

\subsection{Educational research}

In this section, a short overview of educational research relevant for the improvement of the training course is given. Insights into lecture structure and content difficulty are described as well as didactic elements.

An important insight regarding the structure of training courses is the change of attention during the training unit. In lectures, the attention drops sharply after about 10 to $15 \mathrm{~min}$ [18]. Bunce et al. show that attention oscillates between high and low during lectures [19].

Smallwood und Schooler [20] describe mind wandering as a state of decoupling in information processing that occurs due to a shift of attention away from the immediate environment. Investigations of Risko et al. [21] show that the occurrence of mind wandering increases with the time of a lecture and thus the memories of the lecture material diminish.

The so-called sandwich principle as a didactic teaching unit concept can prevent mind wandering. It is based on the systematic alternation of collective teaching phases with a high information density and individual processing phases of what has been learned [22]. While collective teaching phases consist of theoretical input in the form of a lecture by the teacher, the individual processing phases offer a high degree of active design possibilities.

The number and length of the phases are variable and can be designed depending on the content of the teaching unit, the teaching-learning objectives, the duration of the event and the size of the target group [23, 24].

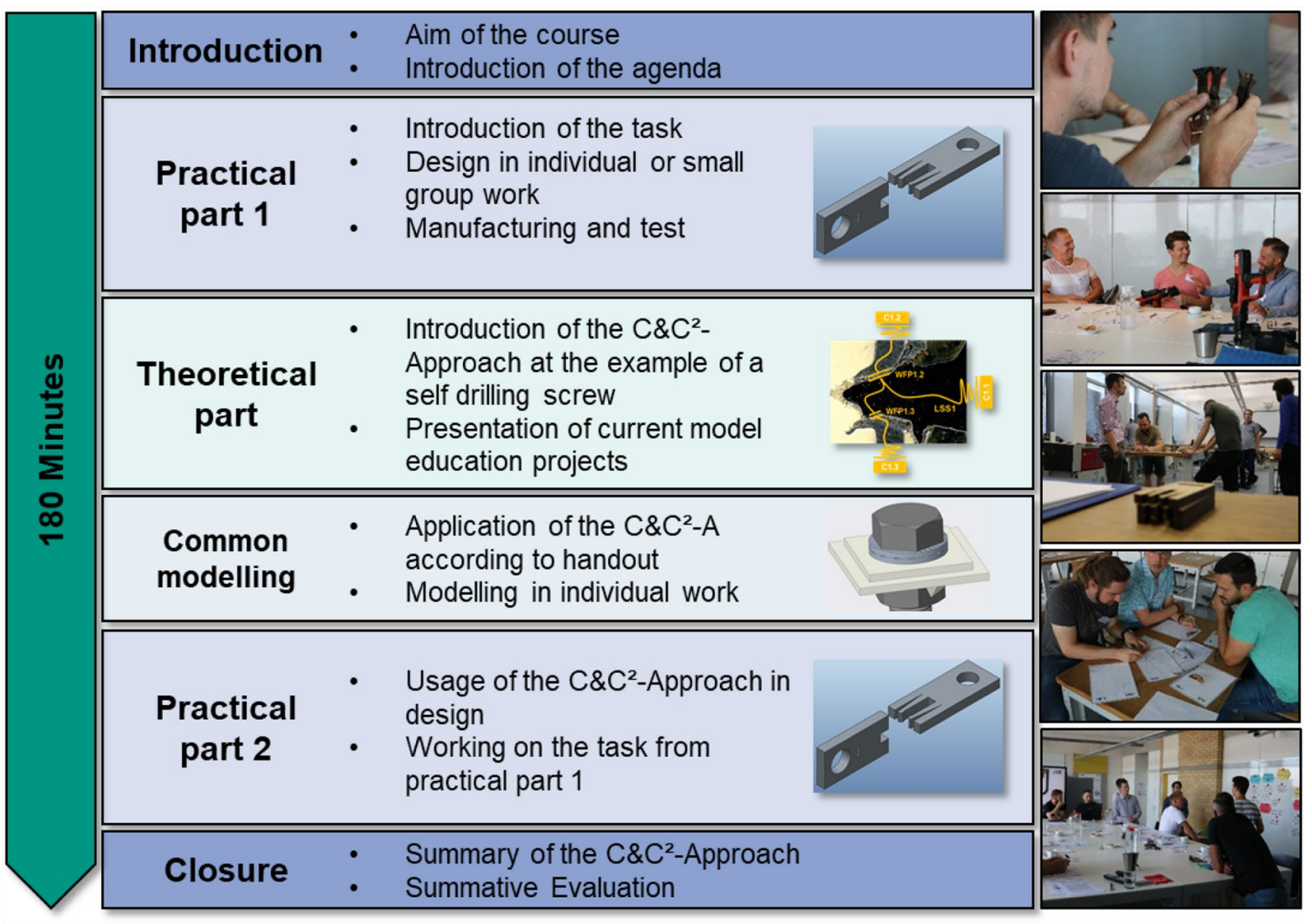

Fig. 2 Procedure of the initial training course concept 
For investigation of the content structure and difficulty of a lecture, the taxonomy of Bloom [25] can be used. This contains a list of six educational objectives, sorted in ascending order of cognitive level. An overview is shown in Table 1.

These levels can be assigned to training course elements and support identification of gaps and leaps in teaching of materials.

Effects of didactic elements on teaching success are described by Hattie in a standardized way through the effect parameter $d$. Negative effects are $d<0$; low to medium positive effects are $d<0.4$; high positive effects are $d>0.4$. [26]

This allows comparison of effect size of different didactic elements. From this study, an excerpt of elements relevant and feasible for the improvement of the training course is shown in overview in Table 2:

\section{Methodical approach}

To answer the research question about crucial aspects to be considered in training courses for qualitative modelling methods for embodiment design, a three step research approach with two field studies is used. The research question How can challenges emerging from a training course for a modelling method be identified and eliminated in embodiment design? is answered through application of the three step research approach at the example of the $C \& C^{2}$-Approach.
In the situation analysis, the existing course concept is used in a field study to train three groups to identify crucial aspects for improvement. Result of this phase are insights from the evaluations of the groups. Then, the improvement takes place. Here, the observations are analyzed and the training course is improved by including solutions from educational research. Result is the improved training course that considers the crucial aspects identified in the situation analysis. In the evaluation, the improved training course is evaluated again to investigate the effects of the improvement on the crucial aspects and identify further research potential.

\subsection{Situation analysis}

During the first field study, the training course concept was held and evaluated in three events with participants of different backgrounds. The course setting was as described in "Concept of the training course for the C\&C2-Approach" section. The participants had different knowledge of the $C \& C^{2}$-Approach ranging from "never heard of it" to "expert in modelling". In the context of this research, the diversity of knowledge levels of the participants is not seen as critical as this might increase the range of uncovered difficulties.

The first event was the "winter school on the $C \& C^{2}$ Approach" in December 2018. This winter school was a one-day event with the aim of bringing together the research community in the field of modelling in embodiment design. Fourteen scientific staff members from
Table 1 Cognitive levels according to bloom [25]

Table 2 Didactic elements from the Hattie study [26] relevant for the training course

\begin{tabular}{ll}
\hline Cognitive level & Explanation \\
\hline Knowledge & Recall facts, methods, processes, patterns and structures \\
Comprehension & Capture and utilize information \\
Application & Use of abstractions in concrete situations \\
Analysis & Clarify structures, connections, relationships of content elements \\
Synthesis & Restructuring/combination of content elements into a new pattern \\
Evaluation & Quantitative and qualitative assessment \\
\hline
\end{tabular}

\begin{tabular}{llll}
\hline Area of subject & Didactic element & $\begin{array}{l}\text { Calculated effect } \\
\text { size d }\end{array}$ & $\begin{array}{l}\text { Source- } \\
\text { meta } \\
\text { analysis }\end{array}$ \\
\hline Visualization & Leave irrelevant elements out & 1.32 & {$[27]$} \\
Visualization & Keywords instead of sentences & 0.99 & {$[28]$} \\
Didactic structure & Formative evaluation & 0.9 & {$[29]$} \\
Visualization & Present common content together on & 0.85 & {$[30]$} \\
Didactic structure & a slide & & {$[31]$} \\
Didactic structure & Group discussion & 0.82 & {$[32-34]$} \\
Didactic structure & Feedback & 0.75 & {$[35-39]$} \\
\hline
\end{tabular}


product development chairs of WiGeP (Scientific community of product development in Germany) participated. Some of the participants have already heard of the $C \& C^{2}$ Approach during their studies or time as research assistants, however none was familiar with its details and the modelling method.

The second event took place as part of the Master's course in power tool design with 18 students from mechanical engineering at the Karlsruhe Institute of Technology (KIT) in the summer semester of 2019. All of the participants have heard of the $C \& C^{2}$-Approach in their lectures. One of the participants used the $C \& C^{2}$-Approach in his bachelors' thesis and had expert knowledge of the modelling.

The third event took place in July 2019 as part of a methods training course for 11 design engineers from a company. Three of the design engineers have studied at the Karlsruhe Institute of Technology and heard of the $C \& C^{2}$-Approach, the others had no knowledge of this approach at all.

As central element of the field study, the evaluation contained the free text evaluation question "what could be improved?" and was conducted at the end of each event. This question lays the basis for the situation analysis. The results of the analysis give an overview about how the training course is perceived by the participants. They show weaknesses of the training regarding its content and structure.

\subsection{Improvement}

The answers are sifted through by the authors and categorized according to thematic similarity. The four topics identified are didactic structure, visualization, content structure and practical modelling. Subsequently, findings from educational research are identified, which can be used to improve the training.

Although the sandwich-structure was already implemented into the initial course concept, it is still used for further improvement regarding the theoretical parts, which are partly longer than recommended. To further investigate the content structure, Bloom's taxonomy (Bloom 1956) is used. It aims at identifying the difficulty of the elements of the training course before an improvement in detail takes place. Regarding didactic elements, factors from the Hattie study [26] as the largest meta-analysis in this field are considered.

Then the assigned solutions are implemented into the training course. For this, at first the structural elements are integrated into the process of the training course. For example, difficult industrial examples are shortened or removed and slots for filling the identified gaps in Bloom's taxonomy are created. Then, each slide of the accompanying presentation is improved regarding the didactic elements and finally the moderation is adapted to the improved course.

\subsection{Evaluation}

The improved training course was held at the IPEK-Institute of Product Engineering as an internal on the job training with 20 scientific assistants. They had 0 to 5 years of experience in engineering design and most of them had already heard of the $C \& C^{2}$-Approach in their study lectures.

The training contents are evaluated in separate questions. The didactic structure is evaluated in the questions (a) to (d).

a) The feedback sessions were helpful for the understanding of the training content.

b) How do you rate the comprehensibility of the documents provided?

c) How do you rate the work in small groups?

d) How is the training course structured?

The visualization is evaluated in the questions (e) and (f).

e) The training contents are clearly arranged.

f) The graphic presentation supports the understanding of the training content.

The practical parts are evaluated in the questions $(\mathrm{g})$ to $(\mathrm{k})$.

g) Did the application examples support understanding of the training course?

h) The tasks in the practical parts were understandable.

i) The practical part consisting of design - manufacturing - testing was supportive for the training course.

j) Practical part 2: The $C \& C^{2}$-Approach was supportive in working at the task.

k) The application guideline was supportive in the second practical part.

In addition, three free text questions are asked:

1. What did you enjoy about the training course?

2. What could be improved?

3. In which activity difficulties or ambiguities emerged?

The evaluation results are analyzed similar to lecture evaluations at the Karlsruhe Institute of Technology (KIT). The answers to the free text questions are the basis for future improvements of the basic training course. The short version and extended training course are not 
evaluated in this contribution and bear therefore potential for further research.

\section{Results}

This section presents the results of the three steps from the situation analysis of the training course to the evaluation of the improved course.

\subsection{Situation analysis}

In this section, at first the analysis of the free text question "what could be improved?" is described, corresponding factors from the Hattie study are assigned and the improved basic training course is described in overview. Then the content analysis regarding its cognitive levels is done by using Bloom's taxonomy. Concluding the modularization is described.

Table 4 shows the answers to the free text question grouped in the four areas of didactic structure, visualization, content structure and practical modelling. The solutions are either corresponding effects from the Hattiestudy or results from brainstorming by the authors.

Bloom's taxonomy was used to obtain an overview of the content structure regarding its cognitive level. The elements of the $C \& C^{2}$-Approach taught in the training course are analyzed and cognitive levels according to the descriptions in Table 1 are assigned. Table 3 shows the cognitive levels of the content of the initial training course concept.

Here, in the column on the left the elements of the $C \& C^{2}$-Approach are listed. The rows are defined as the different cognitive levels according to Bloom's taxonomy (compare also "Concept of the training course for the C\&C2-Approach" section). Addressed elements are marked in blue, not addressed elements in brown.

Especially in the column of comprehension and application, gaps emerged, as the key elements, parameters, the $C \& C^{2}$-Sequence Model and the basic hypotheses are shortly described in the theory part and should then be used in the practical parts. The modelling purpose is addressed on almost every level in the training course except the synthesis, as no new purpose has to be developed by the participants. The analysis techniques and synthesis principles are scarcely addressed at all. For the improvement it is aimed at either limiting the taught knowledge or fill in the gaps between cognitive levels.

\subsection{Improvement}

Based on the situation analysis, at first solutions from educational research are assigned to the difficulties described in Fig. 3. They are grouped to the four topics didactic structure, visualization, content structure and practical

Table 3 Cognitive levels of the content in the initial training course concept

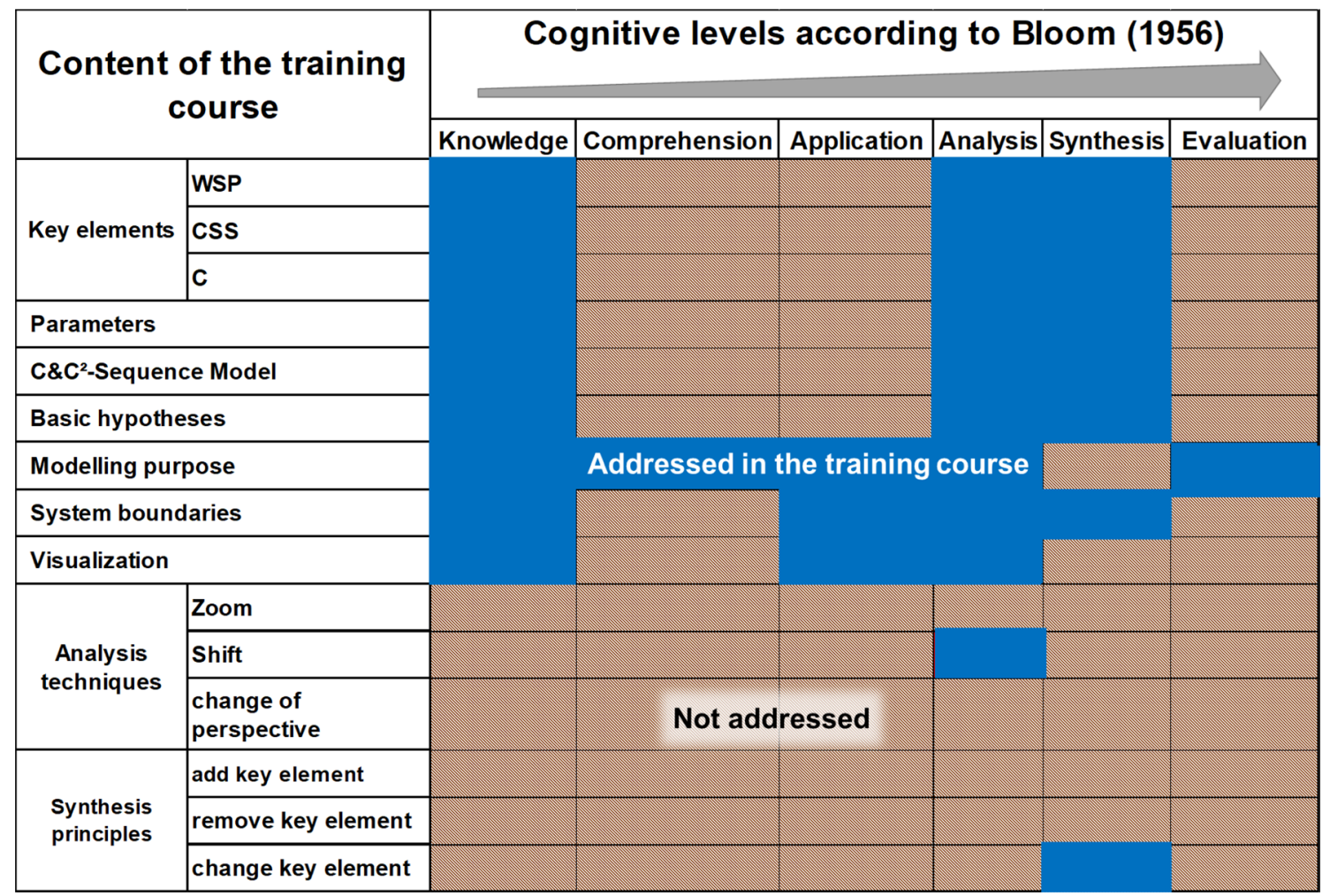




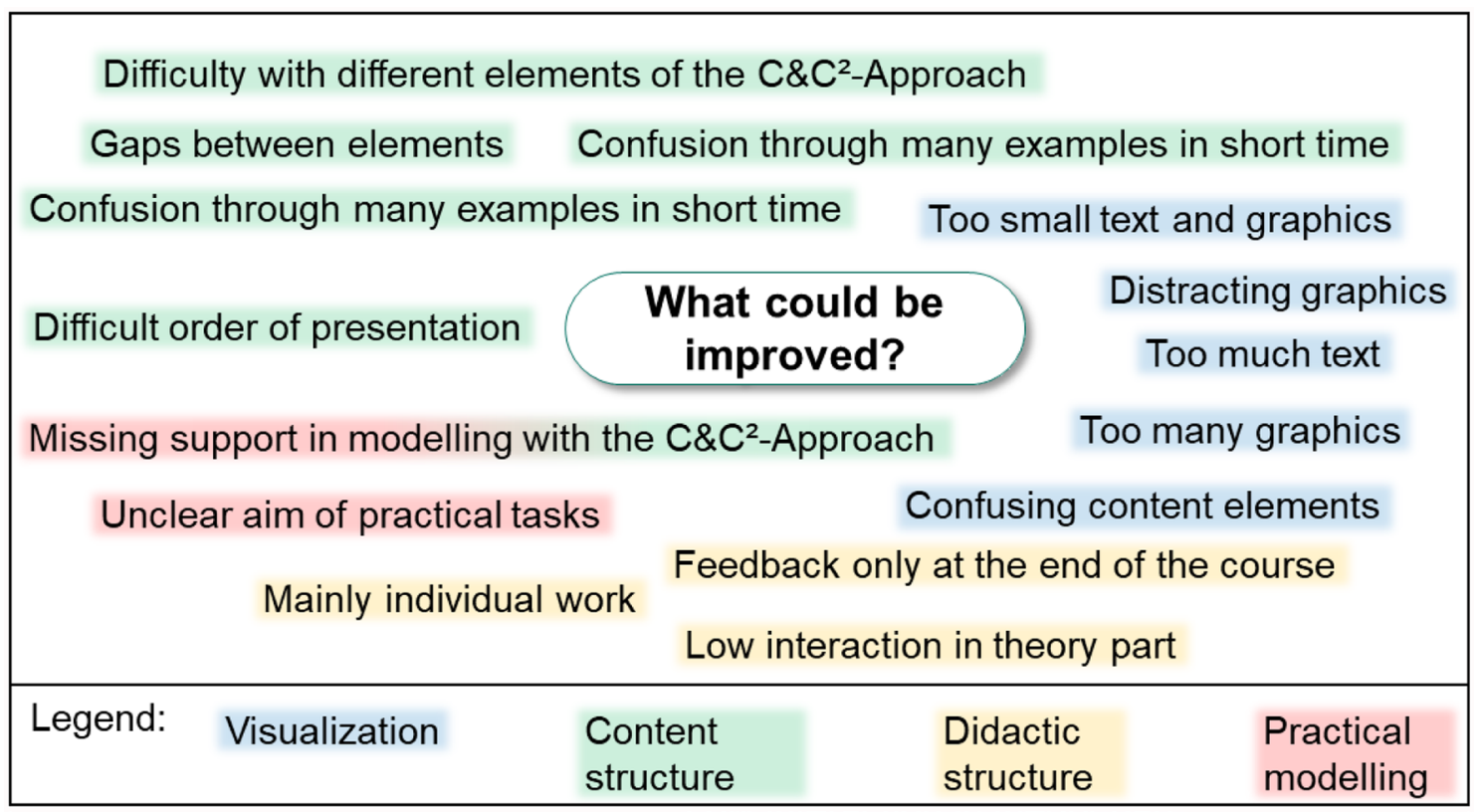

Fig. 3 Identified difficulties from the evaluation

modelling. The solutions have been worked out in detail and are applied to the training course. These results and are shown in Table 4.

From the analysis with Bloom's taxonomy emerges the need for modularization. It is important to enable a comprehensive training of all $C \& C^{2}$-Elements to enable researchers and engineers to use it independently in their work. However, it is impossible to integrate more content into the timeframe of the initial training course.

As a course format similar to the initial training course is necessary for understanding and first application of the $C \& C^{2}$-Approach, the initial course is restructured into the application training course to provide limited content of the $C \& C^{2}$-Approach without gaps in the cognitive levels. With the basic training course and the extended synthesis training course, two modules are then derived from the application training course. Table 5 shows an overview of the content and addressed cognitive levels of the modularized courses.

In the basic training course, the basic elements of the $C \& C^{2}$-Approach are conveyed in about $30 \mathrm{~min}$. The extended synthesis training course contains comprehensive examples for modelling and a wider theory part covering analysis and synthesis activities with the $C \& C^{2}$-Approach. An overview of the developed modules with possible application fields is given in Table 6.

In the following, the application training course is described in detail, as it is the direct successor of the initial training course and thus investigated in the evaluation section.
Content regarding application of the $C \& C^{2}$-Approach in tasks of analysis and synthesis with analysis techniques and synthesis principles has been removed, as this was too difficult to teach in the $3 \mathrm{~h}$ timeframe. The common modelling has been extended by integration of question section, group discussion points, a feedback slide and a formative evaluation. In the second practical part, also small group work and concluding feedback has been added.

In Fig. 4, the application training course is shown in overview. Visual elements of the slides are adapted in the whole presentation accompanying the course. In the first practical part, small group work and a concluding feedback has been added. In the theoretical part, examples have been removed and replaced by teaching of the modelling method. The learning objectives have been reduced to knowledge of the key elements and modelling.

\subsection{Evaluation}

The application training course is held at the IPEK-Institute of Product Engineering with 20 scientific assistants. The summative evaluation addressed the general modelling with the $C \& C^{2}$-Approach, the didactic structure, the visual elements and the practical modelling based on the application examples are described and presented below.

The evaluation questions on the didactic structure of the application training course are shown in Fig. 5 . The questions addressed the feedback rounds, the comprehensibility of the documents and the work in small groups. The didactic elements were rated as very good and helpful 


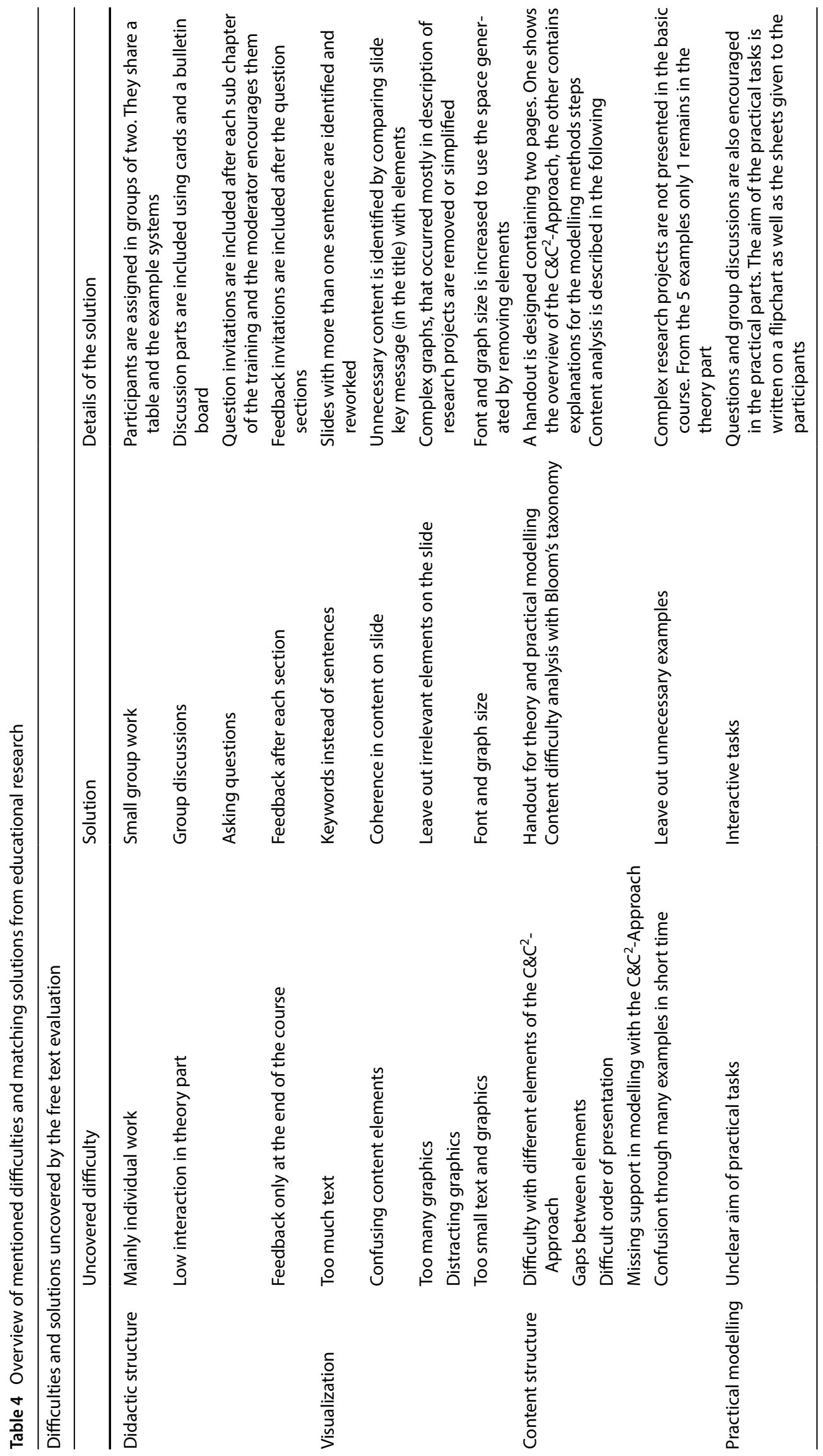


Table 5 Content of the improved and modularized training course

\begin{tabular}{|c|c|c|c|c|c|c|c|}
\hline \multirow{3}{*}{\multicolumn{2}{|c|}{$\begin{array}{l}\text { Content of the training } \\
\text { course }\end{array}$}} & \multirow{2}{*}{\multicolumn{6}{|c|}{ Cognitive levels according to Bloom (1956) }} \\
\hline & & & & & & & \\
\hline & & Knowledge & Comprehension & Application & Analysis & Synthesis & Evaluation \\
\hline \multirow{3}{*}{ Key elements } & WSP & & & & & & \\
\hline & css & & & & & & \\
\hline & c & & ic training cour & rse & & & \\
\hline \multicolumn{8}{|l|}{ Parameters } \\
\hline \multicolumn{8}{|c|}{ C\&C $C^{2}$-Sequence Model } \\
\hline \multicolumn{8}{|c|}{ Basic hypotheses } \\
\hline \multicolumn{2}{|c|}{ Modelling purpose } & & -Annlicatio & ntraining & ourse- & & \\
\hline \multicolumn{2}{|c|}{ System boundaries } & & Aрpilcatio & éming & Unse & & \\
\hline \multicolumn{8}{|l|}{ Visualization } \\
\hline \multirow{3}{*}{$\begin{array}{l}\text { Analysis } \\
\text { techniques }\end{array}$} & Zoom & & & & & & \\
\hline & Shift & & & & \multirow{2}{*}{\multicolumn{3}{|c|}{-Synthesis training course }} \\
\hline & \begin{tabular}{|l|} 
change of \\
perspective
\end{tabular} & & & & & & \\
\hline \multirow{3}{*}{$\begin{array}{l}\text { Synthesis } \\
\text { principles }\end{array}$} & add key element & & & & & & \\
\hline & remove key element & & & & & & \\
\hline & change key element & & & & & & \\
\hline
\end{tabular}

Table 6 Overview of the modules of the training course

\begin{tabular}{|c|c|c|c|}
\hline Module & Description & Duration & Possible field of application \\
\hline Basic training course & $\begin{array}{l}\text { Imparting the basic knowledge of the } C \& C^{2} \text { - } \\
\text { Approach and enabling model building in given } \\
\text { tasks }\end{array}$ & $30 \mathrm{~min}$ & $\begin{array}{l}\text { Studies on the } C \& C^{2} \text {-Approach } \\
\text { Explanation in corporate projects }\end{array}$ \\
\hline Application training course & $\begin{array}{l}\text { Teaching the most important aspects of the } C \& C^{2}- \\
\text { Approach with the ability to build models in the } \\
\text { analysis of technical systems }\end{array}$ & $3 \mathrm{~h}$ & $\begin{array}{l}\text { University teaching } \\
\text { Getting to know the } C \& C^{2} \text {-Approach in the } \\
\text { corporate environment }\end{array}$ \\
\hline Synthesis training course & $\begin{array}{l}\text { Teaching all aspects of the C\&C} C^{2} \text {-Approach and } \\
\text { enabling its independent application in analy- } \\
\text { sis and synthesis tasks of the practical working } \\
\text { environment }\end{array}$ & 3 days & $\begin{array}{l}\text { Further training in the corporate environment } \\
\text { Training of experts in modelling }\end{array}$ \\
\hline
\end{tabular}

by the participants. Their implementation into the training shows a great influence on learning performance from the participants' point of view and confirms the findings from the literature.

As shown in Fig. 6, the training participants were also positive about the evaluation questions on the visualization of the slide contents. The graphic presentation was perceived as clear and supportive for the understanding of the training content and thus confirmed the findings from the research on effective and learning-promoting slide design.

The evaluation questions from the area of practical modelling are shown in Fig. 7. These questions deal exclusively with the application examples and the practical parts of the snap fit connection. The participants found the revised application examples to be a clear support for understanding the training content. Likewise, both the tasks of the practical parts and the structure of the practical parts with design, production and testing were rated positively.

The last two questions were explicitly aimed at the second practical part, where a scattering of evaluations and mediocre results became apparent. In the second practical part, the $C \& C^{2}$ approach and the application guide were only considered to be of limited help in completing the task. A possible reason is the limited time 


\section{Optimized basic training course with implemented elements from educational research}

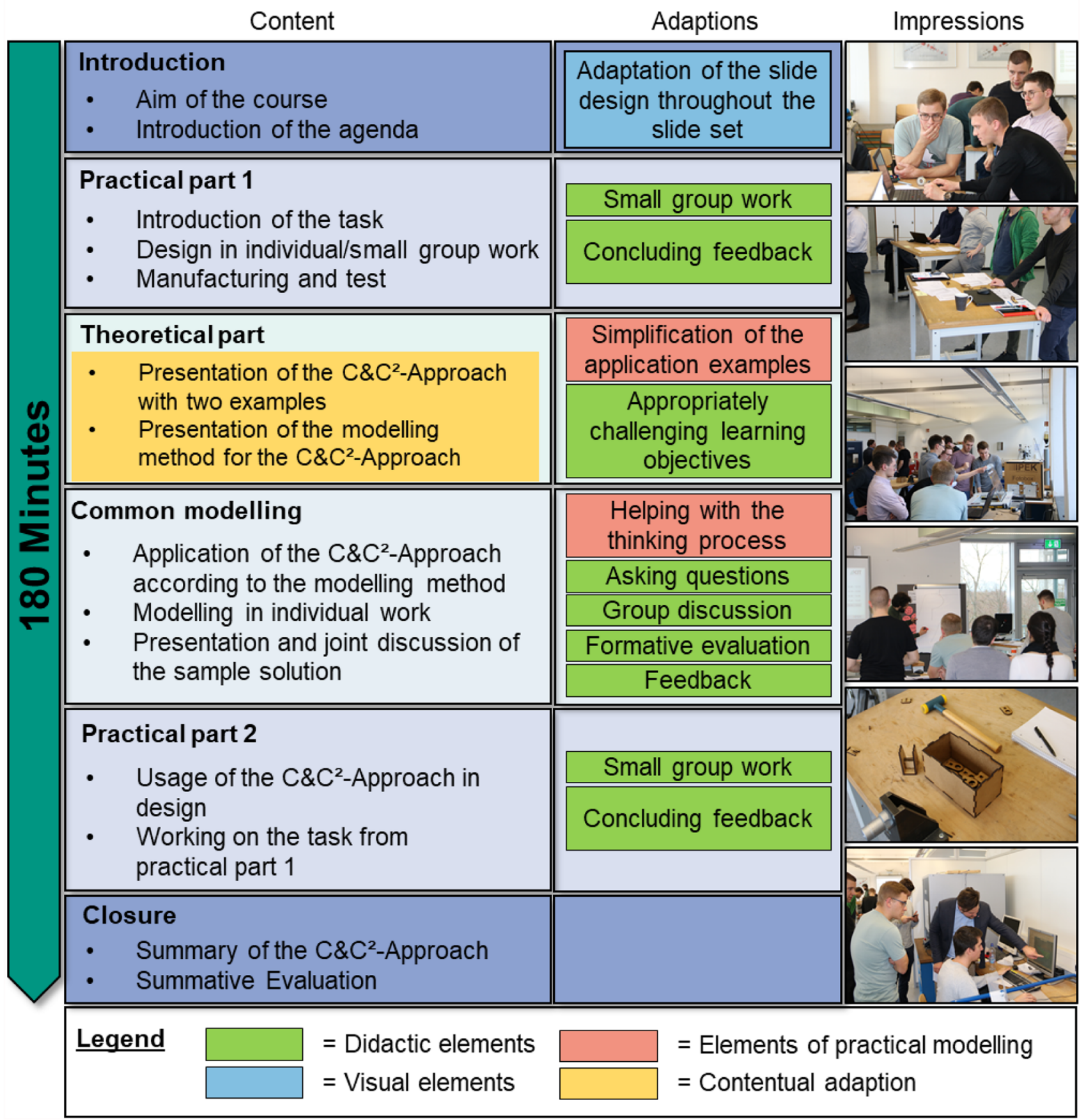

Fig. 4 Application training course with changes from the initial training course

given to complete this task, combined with the emerging bottleneck in the testing procedure (see also remarks in Table 7). The participants were eager to design their ideas as fast as possible and did not use a method, which was still relatively unknown to them and therefore would slow them down.
The answers to the questions asked in the qualitative evaluation are listed in Table 7:

In particular, the operation of the CAD software, which was used to implement the drawn design of the snap-in hook connection, turned out to be a frequently mentioned difficulty. Waiting times at the laser cutter 


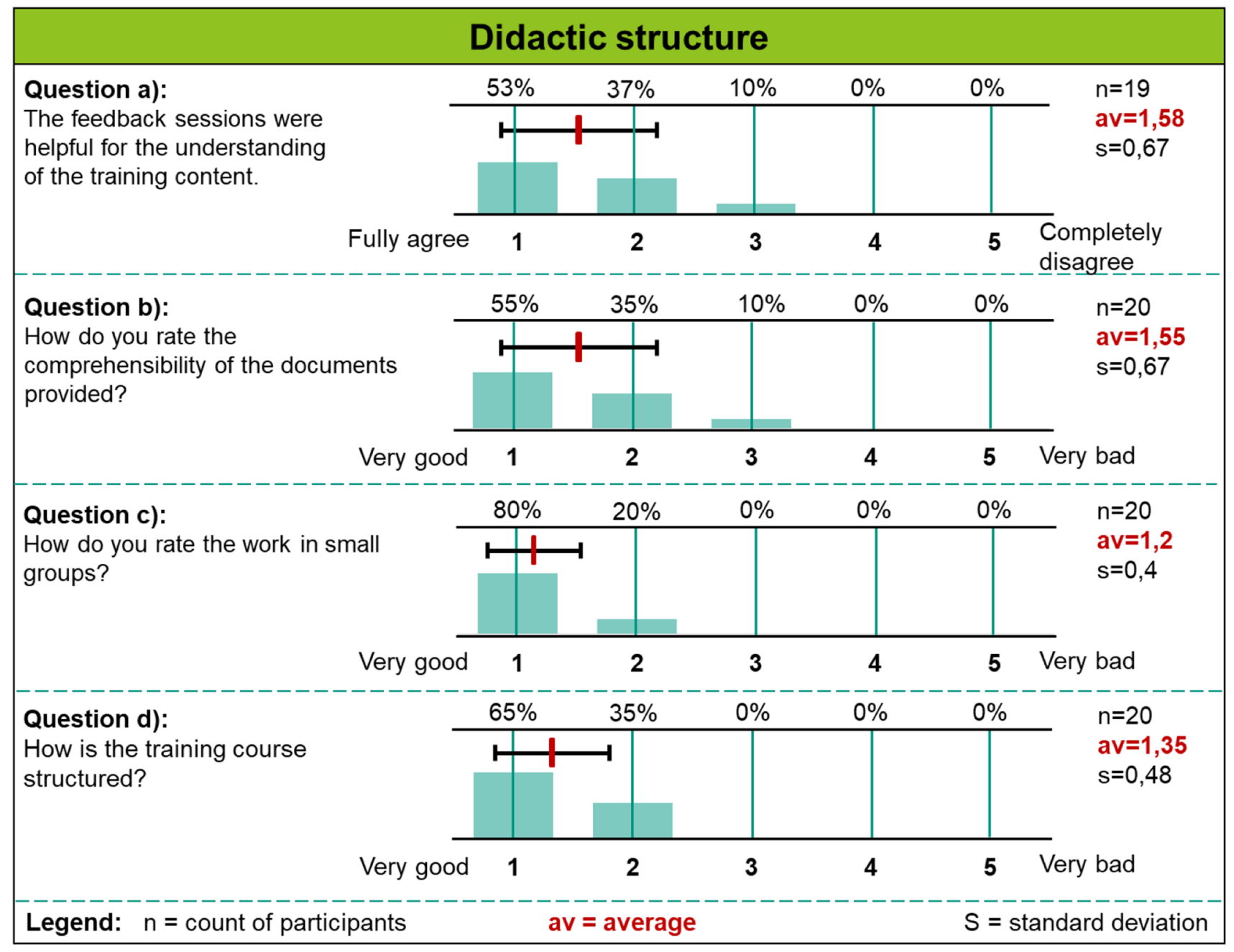

Fig. 5 Evaluation of the didactic structure of the application training course

\begin{tabular}{|c|c|c|c|c|c|c|}
\hline \multicolumn{7}{|c|}{ Visualization } \\
\hline \multirow{2}{*}{$\begin{array}{l}\text { Question e): } \\
\text { The training contents are clearly } \\
\text { arranged }\end{array}$} & $60 \%$ & $35 \%$ & $5 \%$ & $0 \%$ & $0 \%$ & \multirow{2}{*}{$\begin{array}{l}n=20 \\
\text { av }=1,45 \\
s=0,59\end{array}$} \\
\hline & & $\rightarrow$ & & & & \\
\hline Fully agree & 1 & 2 & 3 & 4 & 5 & $\begin{array}{l}\text { Completely } \\
\text { disagree }\end{array}$ \\
\hline \multirow{2}{*}{$\begin{array}{l}\text { Question f): } \\
\text { The graphic presentation supports the } \\
\text { understanding of the training content. }\end{array}$} & $55 \%$ & $40 \%$ & $5 \%$ & $0 \%$ & $0 \%$ & \multirow{2}{*}{$\begin{array}{l}n=20 \\
a v=1,5 \\
s=0,59\end{array}$} \\
\hline & & & & & & \\
\hline Fully agree & 1 & 2 & 3 & 4 & 5 & $\begin{array}{l}\text { Completely } \\
\text { disagree }\end{array}$ \\
\hline Legend: $\mathrm{n}=$ count of participants & \multicolumn{3}{|c|}{ av $=$ average } & & \multicolumn{2}{|c|}{$S=$ standard deviation } \\
\hline
\end{tabular}

Fig. 6 Evaluation results of the visualization of the slide content of the application training course 


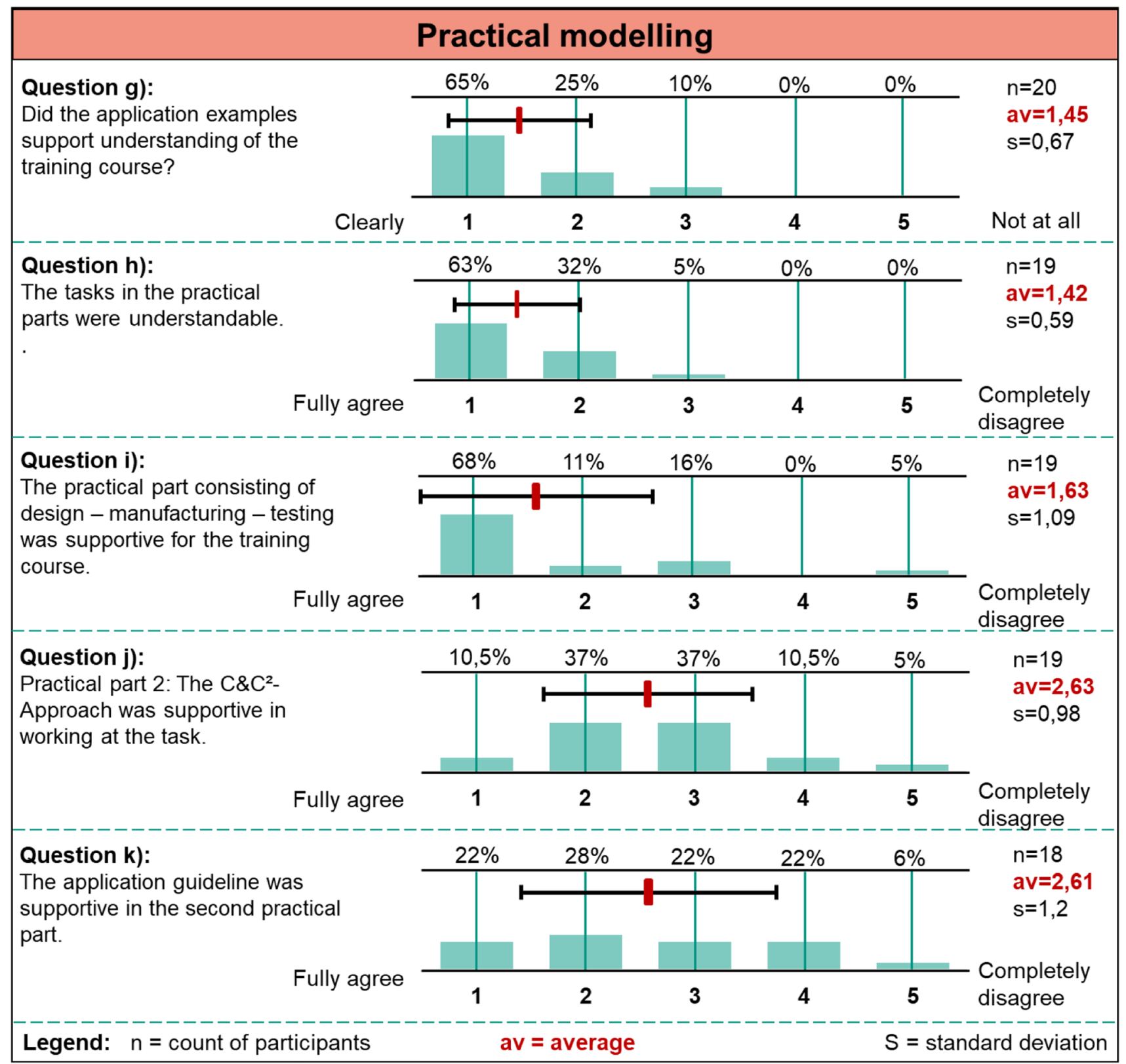

Fig. 7 Evaluation results of the practical modelling of the application training course

were also identified as a problem. In the second practical part, in which the test persons were instructed to use the $C \& C^{2}$-Approach as a supporting measure for solving the set design task, lack of time was mentioned as a frequent problem.

Overall the results can be summarized in the following key statements:

- The sandwich-structure of the training with alternating practical and theoretical phases is helpful and interesting.
- Direct validation using the laser cutter is a great option for practical modelling if the waiting time is short.

- The didactic elements used, such as feedback rounds and small group work support in the understanding of the training course content.

- The visual design elements of the presentation slides improve understanding.

- The temporal structure of the training needs to be adapted in order to improve efficacy of the $C \& C^{2}$-Modelling in the second practical part. 
Table 7 Free text questions for the evaluation

\begin{tabular}{ll}
\hline Question & Answers \\
\hline What did you enjoy about the training & Very interesting overall \\
course? & Direct validation using laser cutter \\
& Many practical activities / proportions of practice and theory \\
& Possibility to try out one's own ideas \\
& Wedge-lock washer (common modelling example) \\
& Small group work \\
What could be improved? & Second practical part was too short / too little time \\
& Waiting time at the laser cutter \\
& Workflow of CAD to manufacturing / bottleneck prototyping \\
In which activity difficulties or ambi- & Examples, where the C\&C ${ }^{2}$-Approach led to improved products \\
guities emerged? & Previous generation leads to design fixation \\
& CAD modelling \\
& Iterative vs. parallel approach in first practical part \\
& Degree of abstraction in the common modelling example \\
& Learning by doing instead of calculations \\
\hline
\end{tabular}

\section{Discussion}

Through the improvement of the training course, the research question How can challenges emerging from $a$ training course for a modelling method be identified and eliminated in embodiment design? can be answered for the example of the training course based on the $C \& C^{2}$ Approach as follows:

The identification of challenges in the four areas of didactic elements, content structure, visualization and practical modelling enabled the purposeful application of elements from educational research.

Regarding didactic elements and content structure, changes of the training course in the improvement were mostly the reduction of overload in the theoretical part. Information from recent projects and new insights about the modelling approach were eliminated as the given information caused confusion of the participants. This was received positively in the evaluation of the improved training course.

In the visualization, the analysis of each slide regarding its elements led to a simplification of the training course and was also perceived positively. Insights regarding the slide design present in educational research could be applied without causing further problems. The additional handout summarizing the key messages supported in following the course and also the independent modelling with the $C \& C^{2}$-Approach. This was also received positively in the evaluation of the improved training course.

The increased alternation of practical and theoretical parts was deemed positive by the participants, leading to a very good evaluation result of the structure of the training course. The implementation of manufacturing in the practical part is challenging for the course moderator and needs support in software implementation. This led to difficulties as not all participants were familiar with the used CAD-system and CAD-CAM intersection (computeraided manufacturing). However, even if it doesn't work perfectly, it seems to greatly improve motivation of the participants. The method usage in the second practical part could be improved by reserving a defined time-slot for working with the $C \& C^{2}$-Approach and the application guideline. This can reduce stress that emerged by the short time given to finish the task and parallel usage of the still relatively unknown method.

The structural analysis using Bloom's taxonomy led to modularization of the training course in three modules. Deeper investigation of the derived modules of the basic training course and the extended synthesis training course has not been conducted due to the boundary conditions of this research project. Therefore, no statements can be made for them. As only the synthesis training course aims at enabling independent modelling in the participants everyday challenges, also no statement can be made whether the participants are able to use the $C \& C^{2}$-Approach in a purposeful way in their everyday work.

A limitation to the evaluation results is, that individual learning processes have not been assessed. As the learners' own motivation, existing level of knowledge and individual use of learning strategies can influence the impact of the training course, they are confounding variables, which have to be considered in further investigations.

In summary, the improvement led to a highly appreciated training course, whose initial flaws could be investigated and partially eliminated by applying insights from educational research. The application training course fulfils 
the aim of generating a support for qualitative modelling in embodiment design by enabling the participants to understand the advantages of the $C \& C^{2}$-Approach and providing tools for initial modelling.

\section{Conclusion and outlook}

In this contribution, a training course for the Contact and Channel Approach as a qualitative modelling approach for embodiment design is investigated and improved. In a three step research approach of situation analysis, improvement and evaluation, insights from educational research are applied.

The effects of conducted measurements are investigated and show that improvements didactical and content structure as well as visualization led to very good evaluation results regarding these aspects. The structural analysis using Bloom's taxonomy led to modularization, as the initial course had gaps in cognitive levels of the presented content, making it difficult to follow the course and limiting the transfer of knowledge.

Potential for further research emerges through the modularization, as the aims of the basic training course and the synthesis training course differ from the application training course and have not been investigated in this research project. Another potential emerges through the integration of manufacturing. Here, potential for smooth operation in the practical modelling shows as difficulties emerged that were caused by software-issues and manufacturing technology.

This research project also presents a reference for the development of other training courses regarding qualitative modelling in embodiment design. Its structure and the implemented insights from educational research can be used in conceptualization of new training courses and the evaluation can be adapted to investigate their efficacy.

Funding Open Access funding enabled and organized by Projekt DEAL.

\section{Declarations}

Conflict of interest The authors declare that they have no conflict of interest.

Informed consent The participants visible in the figures agreed to the usage of the pictures taken during the training course for publication.

Open Access This article is licensed under a Creative Commons Attribution 4.0 International License, which permits use, sharing, adaptation, distribution and reproduction in any medium or format, as long as you give appropriate credit to the original author(s) and the source, provide a link to the Creative Commons licence, and indicate if changes were made. The images or other third party material in this article are included in the article's Creative Commons licence, unless indicated otherwise in a credit line to the material. If material is not included in the article's Creative Commons licence and your intended use is not permitted by statutory regulation or exceeds the permitted use, you will need to obtain permission directly from the copyright holder. To view a copy of this licence, visit http://creativecommons. org/licenses/by/4.0/.

\section{References}

1. TS Schmidt, A Atzberger, C Gerling, J Schrof, S Weiss, K Paetzold (2019) Agile development of physical products: an empirical study about potentials, transition and applicability. Neubiberg: Universitätsbibliothek der Universität der Bundeswehr München

2. Pahl G, Beitz W, Blessing L, Feldhusen J, Grote K-H, Wallace K (2007) Engineering design: a systematic approach. SpringerVerlag, London Limited, London

3. Andreasen MM, Hansen CT, Cash P (2015) Conceptual design: interpretations, mindset and models. Springer International Publishing, Cham, Switzerland

4. E Hilton, W Li, S H Newton, M Alemdar, R Pucha, J Linsey (2016) The development and effects of teaching perspective free-hand sketching in engineering design," in ASME 2016 International Design Engineering Technical Conferences and Computers and Information in Engineering Conference: Volume 3: 18th International Conference on Advanced Vehicle Technologies; 13th, Charlotte, North Carolina, USA

5. Eppinger SD, Browning TR (2012) Design structure matrix methods and applications. MIT Press, Cambridge, Mass, USA

6. Gawthrop PJ, Bevan GP (2007) Bond-graph modeling. IEEE Control Syst Mag 27(2):24-45. https://doi.org/10.1109/MCS.2007. 338279

7. Weber C (2014) Modelling products and product development based on characteristics and properties. In: Chakrabarti A, Blessing LTM (eds) An anthology of theories and models of design: Philosophy, approaches and empirical explorations. Springer, London, pp 327-352

8. Matthiesen S, Grauberger P, Bremer F, Nowoseltschenko K (2019) Product models in embodiment design - an investigation of challenges and possibilities. Springer Nat Appl Sci 1:1-11. https://doi.org/10.1007/s42452-019-1115-y

9. S Matthiesen (2021) Gestaltung - Prozess und Methoden," in Pahl/Beitz Konstruktionslehre, B. Bender and K. Gericke, Eds., 9th ed., Berlin Heidelberg, Germany: Springer-Verlag GmbH

10. Albers A, Wintergerst E (2014) The contact and channel approach (C\&C2-A): relating a system's physical structure to its functionality. In: Chakrabarti A, Blessing LTM (eds) An anthology of theories and models of design: Philosophy, approaches and empirical explorations. Springer, London, pp 151-171

11. P Grauberger et al (2020) Qualitative modelling in embodiment design - investigating the contact and channel approach through analysis of projects," in Proceedings of the 16th International Design Conference DESIGN, Dubrovnik, Croatia

12. Grauberger $P$, Wessels $H$, Gladysz B, Bursac N, Matthiesen S, Albers A (2020) The contact and channel approach -20 years of application experience in product engineering. J Eng Des 31(5):241-265. https://doi.org/10.1080/09544828.2019.16990 35

13. Erbe T (2018) “CPM-Modeling in industry - a reflection”, in design for X. Tutzing, Germany, pp 1-12 
14. B Posner, H Binz, D Roth, NG Vila, J Burkhardt (2016) Systematische Entwicklung von Leichtbau-Lösungen im Maschinenschutz," in Konstruktion - Zeitschrift für Produktentwicklung und Ingenieur-Werkstoffe, Düsseldorf, Germany: Springer-VDI-Verlag $\mathrm{GmbH} \&$ Co. KG

15. Matthiesen S, Grauberger P, Schrempp L (2019) Extended sequence modelling in design engineering - gaining and documenting knowledge about embodiment function relations with the C\&C 2 -approach. Proc Int Conf Eng Des 1(1):1483-1492. https://doi.org/10.1017/dsi.2019.154

16. B Gladysz, A Albers (2018) HOW DO C\& $C^{2}$-MODELS IMPROVE EFFICIENCY, COMPREHENSIBILITY AND SCOPE IN FAILURE ANALYSIS-AN EMPIRICAL STUDY BASED ON TWO LIVE-LABS, in DS92: Proceedings of the DESIGN 2018 15th International Design Conference, Dubrovnik, Croatia, pp. 1127-1138

17. S Matthiesen, P Grauberger, C Sturm, M Steck (2018) From Reality to Simulation - Using the $C \& C^{2}$-approach to support the modelling of a dynamic system, in Procedia CIRP: Elsevier B.V. pp. $475-480$

18. Wilson K, Korn JH (2007) Attention during lectures: beyond ten minutes. Teach Psychol 34(2):85-89. https://doi.org/10.1080/ 00986280701291291

19. Bunce DM, Flens EA, Neiles KY (2010) How long can students pay attention in class? A study of student attention decline using clickers. J Chem Educ 87(12):1438-1443. https://doi.org/10. 1021/ed100409p

20. Smallwood J, Schooler JW (2006) The restless mind. Psychol Bull 132(6):946-958. https://doi.org/10.1037/0033-2909.132.6.946

21. Risko EF, Anderson N, Sarwal A, Engelhardt M, Kingstone A (2012) Everyday attention: variation in mind wandering and memory in a lecture. Appl Cognit Psychol 26(2):234-242. https:// doi.org/10.1002/acp.1814

22. Kaufmann D, Eggensperger P (2017) Gute Lehre in den Naturwissenschaften: Der Werkzeugkasten: Einfach, Schnell, Erfolgreich. Springer, Berlin, Heidelberg

23. Greifeneder R, Zelt S, Seele T, Bottenberg K, Alt A (2012) Towards a better understanding of the legibility bias in performance assessments: the case of gender-based inferences. Br J Educ Psychol 82(Pt 3):361-374. https://doi.org/10.1111/j.2044-8279. 2011.02029.x

24. Deslauriers L, Schelew E, Wieman C (2011) Improved learning in a large-enrollment physics class. Science(New York, N.Y.) 332(6031):862-864. https://doi.org/10.1126/science.1201783

25. Bloom BS (1956) Taxonomy of educational objectives: The classification of educational goals. McKay, New York

26. Hattie J (2010) Visible learning: a synthesis of over 800 metaanalyses relating to achievement. Routledge, London

27. Mayer RE, Fiorella $L$ (2014) Principles for reducing extraneous processing in multimedia learning: coherence, signaling, redundancy, spatial contiguity, and temporal contiguity principles. In: Mayer RE (ed) Cambridge handbooks in psychology, The Cambridge handbook of multimedia learning. Cambridge University Press, Cambridge, pp 279-315
28. Adesope OO, Nesbit JC (2012) Verbal redundancy in multimedia learning environments: a meta-analysis. J Educ Psychol 104(1):250-263. https://doi.org/10.1037/a0026147

29. Fuchs LS, Fuchs D (1986) Effects of systematic formative evaluation: a meta-analysis. Except Child 53(3):199-208. https://doi. org/10.1177/001440298605300301

30. Ginns P (2006) Integrating information: a meta-analysis of the spatial contiguity and temporal contiguity effects. Learn Instr 16(6):511-525. https://doi.org/10.1016/j.learninstruc.2006.10. 001

31. Murphy PK, Wilkinson IAG, Soter AO, Hennessey MN, Alexander JF (2009) Examining the effects of classroom discussion on students' comprehension of text: a meta-analysis. J Educ Psychol 101(3):740-764. https://doi.org/10.1037/a0015576

32. Lysakowski RS, Walberg HJ (1982) Instructional effects of cues, participation, and corrective feedback: a quantitative synthesis. Am Educ Res J 19(4):559-572. https://doi.org/10.3102/00028 312019004559

33. Swanson HL, Lussier CM (2001) A selective synthesis of the experimental literature on dynamic assessment. Rev Educ Res 71(2):321-363. https://doi.org/10.3102/00346543071002321

34. Kluger AN, DeNisi A (1996) The effects of feedback interventions on performance: a historical review, a meta-analysis, and a preliminary feedback intervention theory. Psychol Bull 119(2):254284. https://doi.org/10.1037/0033-2909.119.2.254

35. Redfield DL, Rousseau EW (1981) A meta-analysis of experimental research on teacher questioning behavior. Rev Educ Res 51(2):237-245. https://doi.org/10.3102/00346543051002237

36. Samson GK, Strykowski B, Weinstein T, Walberg HJ (1987) The effects of teacher questioning levels on student achievement. J Educ Res 80(5):290-295. https://doi.org/10.1080/00220671. 1987.10885769

37. Gliessman DH, Pugh RC, Dowden DE, Hutchins TF (1988) Variables influencing the acquisition of a generic teaching skill. Rev Educ Res 58(1):25-46. https://doi.org/10.3102/0034654305 8001025

38. Gayle BM, Preiss RW, Allen M (2006) How effective are teacherinitiated classroom questions in enhancing student learning?", in classroom communication and instructional processes: advances through meta-analysis. Lawrence Erlbaum Associates Publishers, Mahwah, NJ, US, pp 279-293

39. Berkeley S, Scruggs TE, Mastropieri MA (2010) Reading comprehension instruction for students with learning disabilities, 1995-2006: a meta-analysis. Remedial Spec Educ 31(6):423-436. https://doi.org/10.1177/0741932509355988

Publisher's Note Springer Nature remains neutral with regard to jurisdictional claims in published maps and institutional affiliations. 